\title{
Development of a Natural Gas Systems Analysis Model (GSAM)
}

Annual Report

July 1994 - June 1995

July 1995

Work Performed Under Contract No.: DE-AC21-92MC28138

\section{For}

U.S. Department of Energy

Office of Fossil Energy

Morgantown Energy Technology Center

Morgantown, West Virginia

By

ICF Resources, Incorporated

Fairfax, Virginia 


\section{DISCLAIMER}

Portions of this document may be illegible in electronic image products. Images are produced from the best available original document. 


\section{DISCLAIMER}

This report was prepared as an account of work sponsored by an agency of the United States Government. Neither the United States Government nor any agency thereof, nor any of their employees, makes any warranty, express or implied, or assumes any legal liability or responsibility for the accuracy, completeness, or usefulness of any information, apparatus, product, or process disclosed, or represents that its use would not infringe privately owned rights. Reference herein to any specific commercial product, process, or service by trade name, trademark, manufacturer, or otherwise does not necessarily constitute or imply its endorsement, recommendation, or favoring by the United States Government or any agency thereof. The views and opinions of authors expressed herein do not necessarily state or reflect those of the United States Government or any agency thereof.

Available to the public from the National Technical Information Service, U.S. Department of Commerce, 5285 Port Royal Road, Springfield, VA 22161; phone orders accepted at (703) 487-4650. 
This cover stock is $30 \%$ post-consumer waste and $30 \%$ pre-consumer waste, and is recyclable. 


\title{
Development of a Natural Gas Systems Analysis Model (GSAM)
}

\author{
Annual Report \\ July 1994 - June 1995
}

Work Performed Under Contract No.: DE-AC21-92MC28138

For

U.S. Department of Energy

Office of Fossil Energy

Morgantown Energy Technology Center

P.O. Box 880

Morgantown, West Virginia 26507-0880

By

ICF Resources, Incorporated

9300 Lee Highway

Fairfax, Virginia 22031-3349

MASTER

July 1995 


\section{Table of Contents}

$\underline{\text { Page }}$

Abstract $\ldots \ldots \ldots \ldots \ldots \ldots \ldots \ldots \ldots \ldots \ldots \ldots \ldots \ldots \ldots \ldots \ldots \ldots \ldots \ldots \ldots \ldots \ldots$

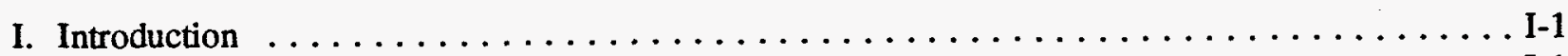

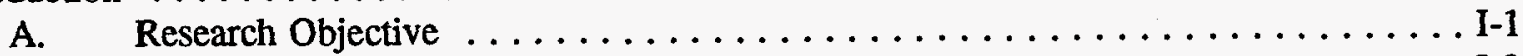

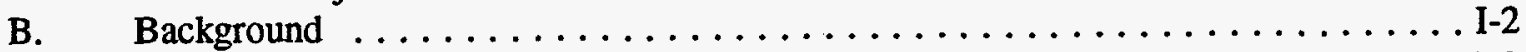

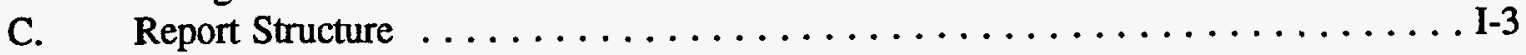

II. Research Methodology $\ldots \ldots \ldots \ldots \ldots \ldots \ldots \ldots \ldots \ldots \ldots \ldots \ldots \ldots \ldots \ldots \ldots$ II-1

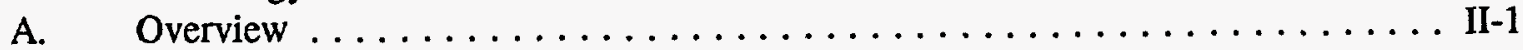

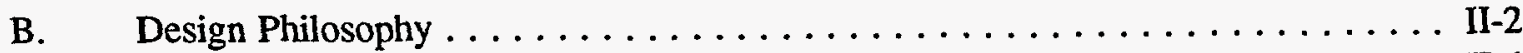

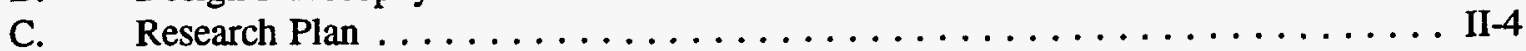

III. Research Activity and Findings . . . . . . . . . . . . . . . . .

A. Methodology Overview and System Capabilities . . . . . . . . . . III-1

1. GSAM Model Methodology . ................... III-3

2. Demand and Integrating Module Methodology $\ldots \ldots \ldots \ldots \ldots \ldots$ III-6

3. GSAM Outputs . . . . . . . . . . . . . . . . . . III-11

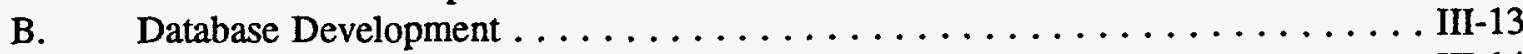

1. Requirements and Purpose $\ldots \ldots \ldots \ldots \ldots \ldots \ldots \ldots \ldots$ III-14

2. Data Development Approach . . . . . . . . . . . . . . . III-14

3. Additional Research Requirements . . . . . . . . . . . . III-15

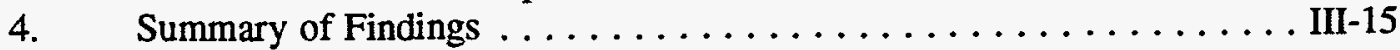

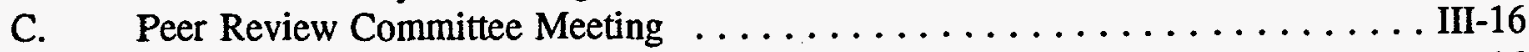

1. Structure and Purpose ...................... III-16

2. Meeting Summary $\ldots \ldots \ldots \ldots \ldots \ldots \ldots \ldots \ldots \ldots \ldots \ldots \ldots$ III-17

3. Results and Recommendations . . . . . . . . . . . . . . III-18

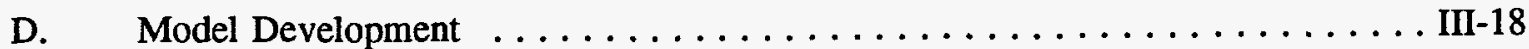

1. Task Objective . . . . . . . . . . . . . . . . . . . . $\ldots \ldots \ldots$

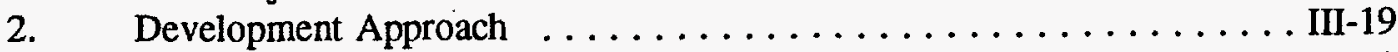

3. Status $\ldots \ldots \ldots \ldots \ldots \ldots \ldots \ldots \ldots \ldots \ldots \ldots \ldots$ III-20

E. Environmental Module Design and Development $\ldots \ldots \ldots \ldots \ldots \ldots \ldots$ III-20

1. Task Objective . . . . . . . . . . . . . . . . . . III-20

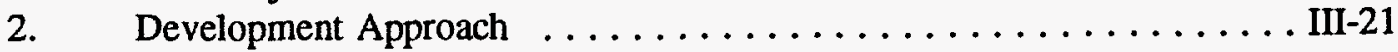

3. Research Completed ...................... III-21

IV. Research Results . . . . . . . . . . . . . . . . . . . . . IV-6

A. Results Achieved During Period of Performance .............. IV -6

B. Research Difficulties and Methods Developed to Overcome Them ......... IV-7 


\section{Table of Contents (Continued)}

Page

V. Planned Research Activities $\ldots \ldots \ldots \ldots \ldots \ldots \ldots \ldots \ldots \ldots \ldots \ldots \ldots \ldots \ldots$ V-1

A. Final Model Integration and Testing $\ldots \ldots \ldots \ldots \ldots \ldots \ldots \ldots \ldots$ V-1

B. Environmental Module ........................... . . . .

C. Resource Data Enhancement . . . . . . . . . . . . . . . . . V-5

D. Model Enhancement and Validation $\ldots \ldots \ldots \ldots \ldots \ldots \ldots \ldots \ldots$ V 6

E. Review Committee Meeting and Follow-up $\ldots \ldots \ldots \ldots \ldots \ldots \ldots$

VI. Conclusions $\ldots \ldots \ldots \ldots \ldots \ldots \ldots \ldots \ldots \ldots \ldots \ldots \ldots \ldots \ldots \ldots \ldots \ldots \ldots \ldots$ VI-1

Appendix A - GSAM Research Work Breakdown Structure $\ldots \ldots \ldots \ldots \ldots \ldots \ldots \ldots \ldots$ A-1

List of Figures and Tables

Figure

III-1 GSAM Structure $\ldots \ldots \ldots \ldots \ldots \ldots \ldots \ldots \ldots \ldots \ldots \ldots \ldots \ldots \ldots$ III-2

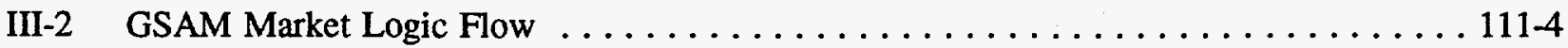

III-3 GSAM Upstream Model Flowchart $\ldots \ldots \ldots \ldots \ldots \ldots \ldots \ldots \ldots \ldots \ldots \ldots$ III-5

III-4 Major Components of GSAM . . . . . . . . . . . . . . . . . III-9

III-5 Analysis of Natural Gas Resources by GSAM Analytical Modules and Databases . . . . III-10

III-6 GSAM Demand Model Flowchart $\ldots \ldots \ldots \ldots \ldots \ldots \ldots \ldots \ldots \ldots$. . . . . . . . . . . .

III-7 GSAM Transportation and Supply/Demand Region Map $\ldots \ldots \ldots \ldots \ldots \ldots \ldots \ldots$ III-12

V-1 Structure of GSAM Environmental Module $\ldots \ldots \ldots \ldots \ldots \ldots \ldots \ldots \ldots \ldots$. . . . . .

V-2 Data Retrieval/Processing Procedure $\ldots \ldots \ldots \ldots \ldots \ldots \ldots \ldots \ldots \ldots \ldots$

V-3 Approach to Environmental Module Development $\ldots \ldots \ldots \ldots \ldots \ldots \ldots \ldots \ldots \ldots$. $\ldots \ldots$

Table

III-1 GSAM Supply Model Components $\ldots \ldots \ldots \ldots \ldots \ldots \ldots \ldots \ldots \ldots \ldots$ III-7 


\section{Abstract}

North American natural gas markets have changed dramatically over the past decade. A competitive, cost-conscious production, transportation, and distribution system has emerged from the highly regulated transportation wellhead pricing structure of the 1980's. Technology advances have played an important role in the evolution of the gas industry, a role likely to expand substantially as alternative fuel price competition and a maturing natural gas resource base force operators to maximize efficiency. Finally, significant changes continue in regional gas demand patterns, industry practices, and infrastructure needs. As the complexity of the gas system grows so does the need to evaluate and plan for alternative future resource, technology, and market scenarios.

Traditional gas modeling systems focused solely on the econometric aspects of gas marketing. These systems, developed to assess a regulated industry at a high level of aggregation, rely on simple representation of complex and evolving systems, thereby precluding insight into how the industry will change over time. Credible evaluations of specific policy initiatives and research activities require a different approach. Also, the mounting pressure on energy producers from environmental compliance activities requires development of analysis that incorporates relevant geologic, engineering, and project economic details. The objective of policy, research and development (R\&D), and market analysis is to integrate fundamental understaniding of natural gas resources, technology, and markets to fully describe the potential of the gas resource under alternative future scenarios.

This report summarizes work over the past twelve months on DOE Contract DE-AC2192MC28138, Development of a Natural Gas Systems Analysis Model (GSAM). The products developed under this project directly support the Morgantown Energy Technology Center (METC) in carrying out its natural gas R\&D mission.

The objective of GSAM development is to create a comprehensive, non-proprietary, microcomputer model of the North American natural gas system. GSAM explicitly evaluates the key components of the system, including the resource base, exploration and development practices, extraction technology performance and costs, project economics, transportation costs and restrictions, storage, and 
end-use. The primary focus is the detailed characterization of the resource base at the reservoir and subreservoir level. This disaggregation allows direct evaluation of alternative extraction technologies based on discretely estimated, individual well productivity, required investments, and associated operating costs. GSAM's design allows users to evaluate complex interactions of current and alternative future technology and policy initiatives as they directly impact the gas market.

GSAM development has been ongoing for the past three years. The overall development effort was recently extended for two years to allow implementation of recommendations of an industry Peer Review Committee. Research findings to date have focused the design work on critical data and model segments required to fully evaluate future market conditions. The contract also includes the development, testing, and integration of an environmental analysis module, including data development, analytical methodology, and full integration into GSAM. This work is currently being completed in coordination with DOE's Metairie Site Office (MSO). The full development of GSAM also now includes the finalization of reservoir level databases. Initial data development is complete with enhancements being planned for key regions and resource segments.

The highlight of the past year was the successful completion of the Peer Review meeting. The committee chosen represented a broad spectrum of the gas industry, including producers, end-users, institutions, various government agencies, and universities. The two day meeting covered all aspects of GSAM from data development to complex analytical procedures. The committee was split into subgroups to allow a more detailed look at key segments of the overall system. Recommendations of the committee were presented at the end of the meeting and summarized in a report for METC.

Key activities completed during the past year include:

- Licensed and screened NRG Associates Significant Oil and Gas Fields of the United States reservoir database

- $\quad$ Finalized and tested reduced form reservoir model production type curves

- Finalized database structures for use in GSAM and linkage to other systems

- Integrated and tested the exploration module

- $\quad$ Collected and updated upstream capital and operating cost parameters 
- $\quad$ Finalized downstream/demand models

- Presented initial model design to a Peer Review Committee

- Prepared response to Review Committee comments

- Presented research results at METC Contractor Review Meeting

- $\quad$ Conducted other briefings for METC and DOE/HQ managers

- Delivered draft User's Guide, models, and databases for METC use and testing

- $\quad$ Conducted initial training on modeling methodology at METC.

Initial databases have been used to integrate and test all interfaces between modules. Adjustments to the models based on review by METC and the Peer Review Committee have been implemented or planned for the near future. Final documentation of the full system is nearly complete.

GSAM development continues on schedule and will continue to provide analytical capabilities in R\&D planning and policy review in the coming year. Additional system enhancements will be beneficial to allow the system to quickly and thoroughly analyze the evolving domestic gas market. The GSAM Environmental Module development, integration, and testing is also moving ahead as planned. This enhancement, along with the full development of a comprehensive resource database, allows METC to significantly focus its natural gas R\&D program, credibly respond to policy initiations, and provide the most valid and comprehensive assessments of the North American gas market available. 



\section{Introduction}

This report reviews the goals, work plan, schedule, and accomplishments of research under the Department of Energy (DOE) contract DE-AC21-92MC28138, Development of a Natural Gas Systems Analysis Model (GSAM). The work has been underway for three years, since June 22, 1992. Work previously performed under this contract included review of existing and emerging technologies and critique of other available models. During the recent period ICF completed the final design of the model, developed and initially tested the databases, entered various engineering and cost modules, and developed market model interfaces.

This report provides an overview of the activities to date and schedule for future testing, validation, and authorized enhancements. Its goal is to inform DOE managers of progress in model development and to provide a roadmap for on-going and future research. The findings reported are consistent with the Project Review presentation and demonstration at the Morgantown Energy Technology Center (METC) contractor review meeting in April.

\section{A. Research Objective}

The objective of this research effort is to create a comprehensive, non-proprietary, microcomputer model of the North American natural gas market. GSAM is designed to explicitly evaluate components of the natural gas system, including the entire in-place gas resource base, exploration and development technologies, extraction technology and performance parameters, transportation and storage factors, and end-use issues. The system, once fully developed, tested, and validated, will be used to evaluate alternative research and development (R\&D) activities and strategies under the direction of METC.

The scope of the effort has been expanded to include resource data development, construction of an environmental module, and limited applications. This two-year effort will provide additional capabilities of the model and address concerns expressed by reviewers. The goal is to provide DOE with the most comprehensive tool possible for assessing the R\&D program. GSAM can now provide the 
analytical capability to estimate the impacts of federal energy and environmental policy initiatives on domestic gas potential. The initial project has been extended to further develop unique system capabilities. Final development and testing is under way.

\section{B. Background}

The domestic gas market has undergone dramatic economic and technical evolution in the past decade. This change in the way business is conducted has significant implications for the extraction potential of the natural gas resource, due to both upstream supply considerations and downstream demand requirements. DOE's natural gas research must address these new market realities.

In December 1993, DOE published the Domestic Natural Gas and Oil Initiative (DNGOI) and Natural Gas Strategic Plan. These two documents contain important guidance on R\&D direction to ensure that the gas program is appropriately focused on key activities of interest to improve the gas industry with minimum duplicative effort. The overall goal of the gas program, to improve the ability of the domestic gas market to supply, store, transport, distribute, and utilize gas in an economically efficient manner, must be met through strategic direction that appropriately reflects and accounts for market realities. The DNGOI recognizes the important role natural gas will play in the future. It lists strategic activities and specific actions focused on advancing and disseminating technology and stimulating markets related to natural gas. GSAM will provide analytical background and strategic planning capabilities needed to meet many of the DNGOI requirements. Without an analytical tool like GSAM, R\&D activities cannot be appropriately ranked or focused on the most important aspects of natural gas extraction efforts or utilization considerations.

The expanded design of GSAM, including environmental analysis capabilities and a more complete resource description, also meets important strategic objectives identified by DOE. To be utilized in today's market, technology advances must be environmentally sound and prudent. Also, more R\&D is being focused directly on environmental damage mitigation. As regulations become more complex, interrelated, and cumbersome, the analysis of environmental policy and R\&D activities will increase in importance. GSAM will be ready to assist DOE managers in program focusing and review. 
DOE's Natural Gas Strategic Plan requires that R\&D activities be evaluated for their ability to provide adequate supplies of reasonably priced gas. GSAM provides the capability to assess potential and on-going R\&D projects using a full fuel cycle, cost-benefit approach. This method provides realistic, market-based assessments of benefits and costs of alternative or related technology advances. It can estimate both technical and commercial successes, quantifying the potential benefits to the market, as well as to other related research. GSAM, therefore, represents an integration of research activities and a method for planning and prioritizing efforts to maximize benefits and minimize costs.

\section{Report Structure}

This annual report summarizes the purpose, work, and results of research activities during the period of performance, June 22, 1994 to June 21, 1995. Section II describes the research methodology, including how it has progressed as DOE's strategic direction has shifted, and as new findings have focused model development efforts. Section III provides a discussion and summary of research activities for the four major task assignments on which work has been done during the reporting period. Section IV summarizes the results of the research efforts, including difficulties encountered and methods used to overcome them. Section V provides details about planned activities in the coming year. These include final GSAM integration and testing, resource data development, environmental module research, and a second review committee meeting, each of which is discussed. Appendix A provides additional detail on the research work plan for the remainder of the contract and individual task activities for the entire project, including the recently approved extension. 


\section{Research Methodology}

\section{A. Overview}

The primary purpose of GSAM is to provide credible, valid empirical support to METC R\&D program planning and policy assessment. This role has become increasingly important as DNGOI and other government and industry initiatives call for more detailed analysis of alternative strategies. GSAM development is being coordinated to ensure that the highest quality product possible is delivered in a timely manner. In addition, consistent review and input from METC has been sought to maximize future DOE use of GSAM's capabilities.

Where appropriate, GSAM development adapted and consolidated many existing analysis models. Significant efforts were committed in order to define the analytical needs, assess what models and data are currently available, and develop logical, cost-effective methods to convert and link various elements into an integrated design. The focus of GSAM development, however, has not been limited to currently defined needs and analytical requirements, nor has the system been narrowly defined to address a confined set of conditions. Rather, the models, databases, reports, and input procedures have been developed to assure maximum flexibility and future use of the system.

Environmental compliance costs are expected to increasingly influence operator decision-making. Costs associated with land management, drilling waste disposal, emission controls, and underground injection control (UIC) are a function of the regulatory requirements imposed at various levels. GSAM has been enhanced to analyze the direct cost of environmental compliance on future investments and operating costs as a function of the restrictions imposed, the unique location of the reservoir, and the general operating conditions. The expanded analytical capability to determine increases in compliance costs as a function of the regulatory scenario imposed on operators in various regions has been fully developed. This capability has been added to all modules of GSAM and is currently being tested.

Data development efforts, initiated only during the past year, have resulted in the creation of a comprehensive data base of non-associated gas reservoirs for analysis in GSAM. This included the 
licensing and incorporation of NRG Associates' Significant Oil and Gas Field of the United States database, the evaluation and description of the undiscovered resource based on the U.S. Geologic Survey assessment, and the addition of representative reservoirs for Canada, Appalachia, and some offshore regions. The result has been the rapid development of a preliminary data source for testing and calibrating GSAM. Recently approved extension of the contract will result in updating and further enhancement of the overall GSAM database.

The Peer Review process was also initiated during the past year. The initial committee, consisting of 15 members from industry, government, institutions, and academia, met in Pittsburgh in October. The two day meeting covered all aspects of GSAM modeling and data development. The committee presented specific recommendations for expansion and enhancement of GSAM. The results were documented for METC and the concerns of the committee addressed in the work plan for the extension of the GSAM development contract.

Initial installation and training on GSAM was completed during the past several months. The entire system of data and models has been installed at METC and a two day training session held in May. Additional updates to the model have been provided since the initial installation and training sessions are planned to assist METC and its support contractor in using GSAM.

GSAM development has also been planned and designed to be timely and responsive. Development was significantly accelerated to provide analytical capabilities to assist METC in planning new initiatives. Also, the final methodology developed and discussed below was selected because of the speed and flexibility it provided in completing this research.

\section{B. Design Philosophy}

The design foundation of GSAM is designed to prevent obsolescence and provide for ongoing enhancements. GSAM has been developed in discrete modules that are linked, but can be validated and used on a stand-alone basis. This design feature was selected to assure easy updating and enhancing of the system as new information and procedures become available. Additionally, GSAM uses a series of component databases, each specifically designed to allow separate updates as new data become available. The database structures have been generated to ensure consistency between different segments. 
Because the analyses needed for a full GSAM run are so complex, GSAM incorporates various modules that perform the computer intensive resource and reservoir-level modeling prior to the userinitiated GSAM run. Based on expected future analysis needs, alternative scenarios (e.g., various R\&D, tax, or market strategies) can be modeled using the GSAM Reservoir Performance Module. This allows the user to quickly analyze multiple technology, policy, or tax situations and store results for future use. This potentially reduces GSAM nun-times by more than 80 percent in evaluations of multiple R\&D in policy strategies. The preprocessor output data are configured to accommodate changes in market conditions that would require new analysis in traditional models. The full explanation of these concepts is described in the Model Development Topical Report.

GSAM models the upstream natural gas system at the level at which operators make investment and technology selection decisions: the individual reservoir. Each component of the upstream evaluation methodology accommodates this level of detail:

- The resource base is characterized as individual reservoirs with average effective reservoir properties and, for known reservoirs, complete drilling and production histories. These units are further subdivided where appropriate to reflect intra-reservoir heterogeneities.

- Engineering costs and investment requirements are derived based on regions, depth, and operating conditions of each zone.

- Technology is characterized in terms of the explicit performance that affect gas contact, flow rates and ultimate recovery, and cost parameters that are associated with applying a group of technologies in the specified reservoir setting.

- Production modeling accounts for unique interactions of geology, technology, and operating practices that influence gas recovery rate and ultimate volume for individual wells and reservoirs.

- Project economics are evaluated on an industry-standard after-tax pro-forma basis for both full and incremental project bases. Projects are costed at the level of the commonly used authorization for expenditure evaluated under explicit timing and amounts of capital, operating and tax costs, and revenue streams.

- Decision-making incorporates the inherent uncertainties and inefficiencies in technology performance and gas markets.

Each component of GSAM incorporates the capability to evaluate the inherent uncertainties in resource characterization, technology application, reservoir performance, market economics, and operator 
decision-making. Two important benefits of including explicit risk analysis in GSAM are to provide insights into the value of better information and to estimate the range of possible outcomes of current or proposed policies under alternative resource, technology, or market scenarios.

Analysis of downstream issues such as gas demand, transmission, storage, imports, additional gas sources, pipeline capacity additions, and interfuel competition are aggregated to the regional level. The GSAM Integrating Model uses a linear programming minimization routine to balance demand in various regions based on available supplies. The model then estimates future gas price tracks by region in order to balance supply and demand at the least cost to the user. The model also estimates future expansion of gas transportation capacities across the pipeline network. This market dynamic model is a key component of the assessment of future technology applications. It allows analyses to directly consider the market impact on future gas prices, and therefore project economics of recovery operations.

\section{Research Plan}

Design and development of a model of this complexity required a detailed research plan and corresponding management controls. For this project, we developed a research Work Breakdown Structure (WBS) and integrated this into a critical path method (CPM) management plan. Appendix A contains the summary WBS developed for the current research. Efforts are underway to complete a comprehensive cost and management plan and contract plan for the extended contract period. These will be submitted to METC in the next few weeks. The CPM work schedule will continue to be updated weekly and used to sequence and manage project activities.

Research over the past year was conducted in five distinct tasks (1) develop GSAM methodology, (2) design and test models, (3) review the system with industry experts, (4) develop the environmental module, and (5) complete an initial test database. Details on each of these activities is summarized in the next section. Greater detail is provided in separate topical reports on each activity, the first three of which have already been delivered.

The recent modification to the contract to add to the capabilities as recommended by the Peer Committee will substantially enhance GSAM. The data development efforts, application for planning and policy analyses, and selected improvements to the models will aid future METC R\&D efforts. 


\section{Research Activity and Findings}

This section summarizes the research completed and preliminary findings during the reporting period just completed. Work was continued on four tasks of GSAM. Work under each of these tasks is described below. The integration of these individual research efforts is summarized in the next section and in the GSAM design task. A separate section on the Environmental Module development is also included. Work under the recently approved extension of the contract has been focused only on planning of future tasks and research for completion in the next reporting period.

\section{A. Methodology Overview and System Capabilities}

The domestic gas market is an integrated, commodity-based system of supply, transportation, and demand. Regulatory changes have dramatically altered the once highly regulated gas industry. Demand and supply of gas are influenced and limited by market conditions and regional boundaries established by the existing infrastructure. GSAM has been designed and developed to fully assess, both regionally and nationally, the benefits and costs associated with the flow of gas from the reservoir to various end-users. Figure III-1 provides a schematic overview of GSAM's major analytical components. Each of these five GSAM components is summarized below.

The domestic gas resource is large, diverse, and widely dispersed, both geologically and geographically. E\&P efforts encompass a broad range of activities and technologies. Many of these are explicitly designed for the specific characteristics of particular prospects or resources. Each is designed to improve the producibility and economics of the domestic natural gas resource. To fully meet its objective and assist DOE R\&D managers, GSAM must consistently address both conventional and unconventional gas resources and the many processes used to find, extract, and process natural gas for sale.

To maximize both validity and credibility, GSAM's proposed methodology evaluates each activity as an investment opportunity at the appropriate unit of analysis. Exploration is evaluated on a fully risked prospect basis. For exploration to be conducted, the expected value of the next discovery must exceed 
Figure III-1. GSAM Structure

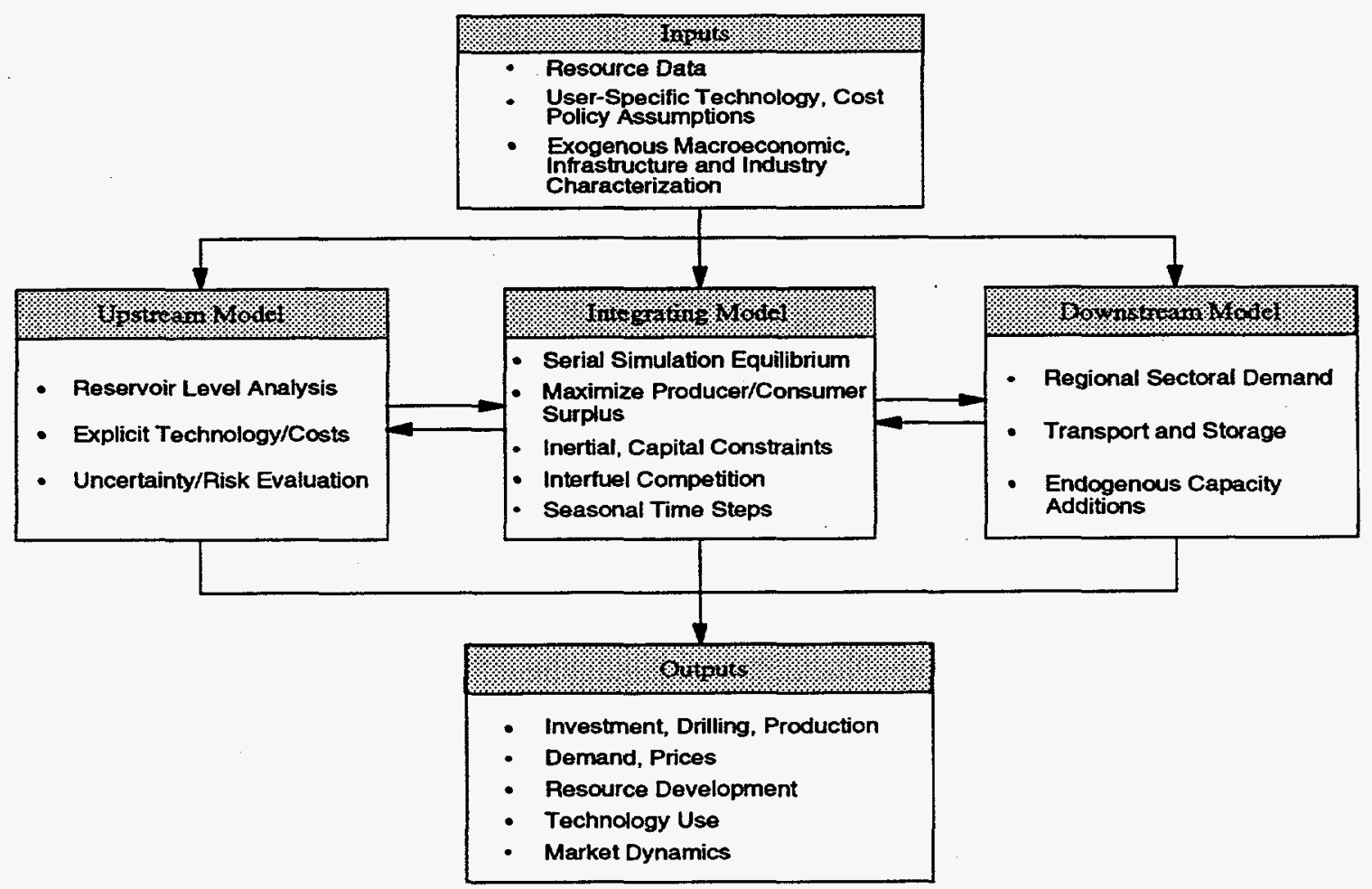

the full cost of finding hydrocarbons (including dry holes) and ultimately developing and producing the potential discovered reservoir(s). Once a reservoir has been discovered, development and production from that reservoir must generate expected revenues to cover the investments, operating costs, and risks of development. Each investment decision is approached from the view point of an operator determining if the investment is warranted. These evaluations integrate detailed information on reservoir geology, technology applications, productivity, costs, and market prices -- the same information an operator uses in the field to select projects. Additionally, transportation and demand decisions are modeled from the viewpoint of the appropriate decision-maker, each attempting to maximize fully-risked profit in a market context.

GSAM integrates these discrete decisions into a market framework. Investment decisions are evaluated based on contemporary market conditions (e.g., capital and rig availability, wellhead prices) consistent with the supply and demand of gas and the availability of infrastructure in various regions. E\&P activity that creates market imbalances (e.g., excess supply in a given region) must cover not only the direct extraction costs but the additional costs of transporting the gas to its end-user. Based on aggregate activities in various supply and demand regions, GSAM equilibrates regional markets and prices 
over the forecast period. Figure III-2 displays a simple overview of GSAM's market balancing approach. The downstream model also explicitly addresses seasonal demand fluctuations that influence gas infrastructure, storage, and utilization capacity and investment decisions.

\section{GSAM Model Methodology}

The consistent evaluation of gas supply, demand, and transportation under alternative economic, technology, and regulatory conditions is a key objective of GSAM development. Figure III-3 provides a detailed view of the analytical framework of eight databases and eight engineering and costing modules comprising the logic flow of the Model. The integrated, modular design of data and analytical procedures maximizes flexibility in organizing, designing, implementing, and completing analyses. This structure also allows efficient model/data maintenance and enhancements in response to priorities derived from initial GSAM analyses and evolving gas R\&D program direction.

The remainder of this section provides an overview of the entire model. GSAM is grouped into five functions:

- Resource Module. Available resource, play, and reservoir data are transformed into fully characterized play-specific groups of known and undiscovered reservoirs.

- Reservoir Performance Module. All reservoirs are fully evaluated under all plausible alternative technology, economic, and development scenarios.

- Exploration and Production Module. In response to market signals generated by the GSAM Demand and Integrating Module or user specified input, allocates exploration, development, and production activity over the forecast period.

- Demand and Integrating Module - evaluates demand for gas by region, sector, and season as a function of gas prices, population growth, economic activity, interfuel competition, and other regional and national factors. Creates input files for operating the linear program to balance supply and demand across a nationwide transportation network linking supply regions and demand areas.

- Production and Accounting Module - converts output from other modules to provide a full accounting of all exploration, drilling, completion, operations, and upstream activities. Output provides details on annual gas production, gross revenues, taxes, investments, operating costs, and operating profits. 
Figure III-2. GSAM Market Logic Flow

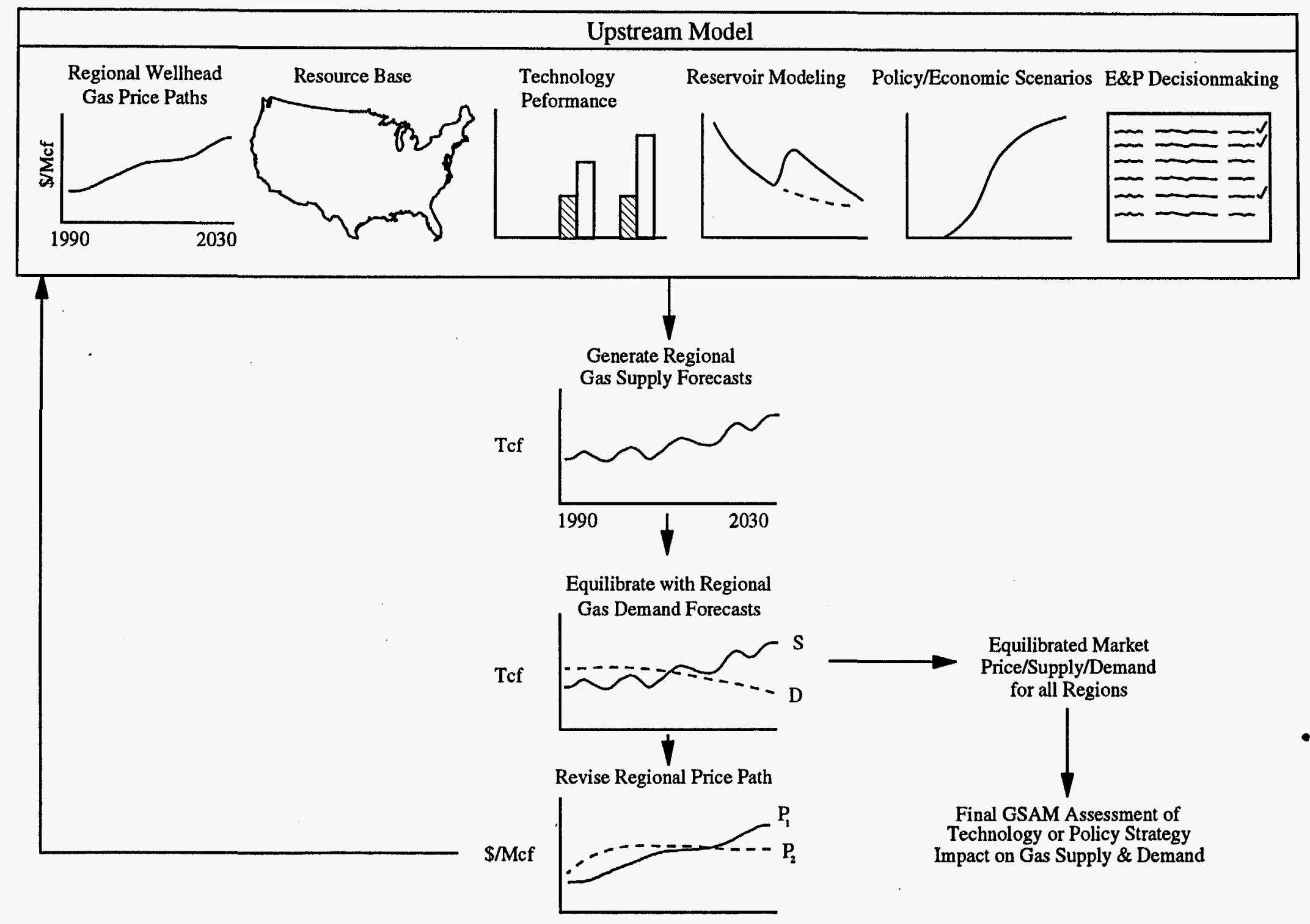


Figure III-3. GSAM Upstream Model Flowchart

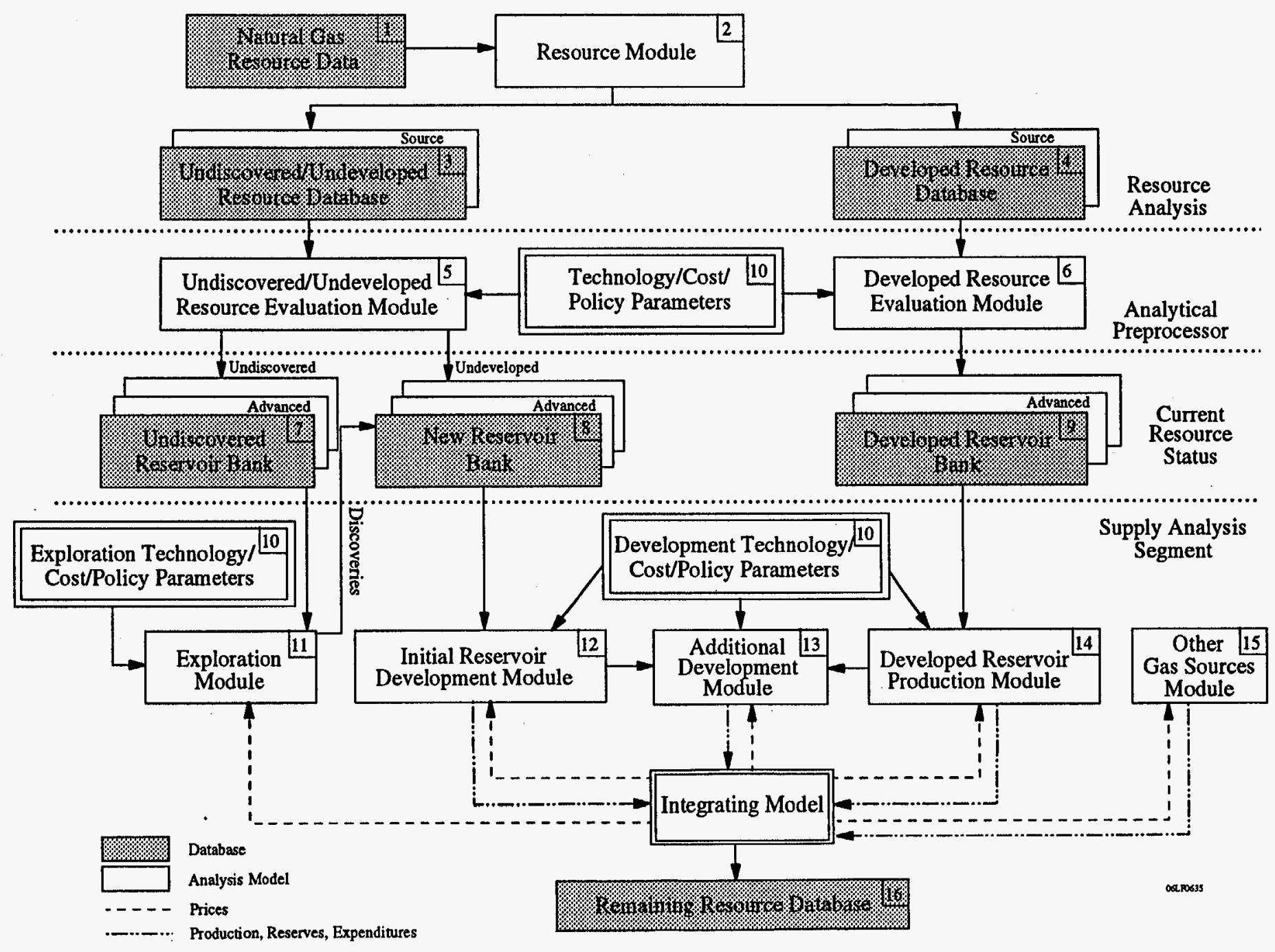


Table III-1 provides descriptions of the individual modules and databases that comprise the entire Upstream Model.

The normal process of operating GSAM is shown in Figure III-4. The GSAM design and development also emphasizes the importance of proper accounting of resources by describing, quantifying, and evaluating the remaining domestic gas resource after production by selected technologies. The modular design provides an easy tracking capability within the model to monitor how technology is influencing gas recovery from various resource segments (Figure III-5). The Remaining Resource Database provides a balanced, accountable description of gas remaining to be recovered in various reservoir settings. These resources are targets for more aggressive R\&D to overcome key physical or economic barriers to production. A key feature of GSAM is its ability to describe resources in terms of gas-in-place. Past reliance on recoverable gas as a unit of analysis has confounded the estimation of the impact of technology on reserve growth and recovery efficiency.

GSAM's modeling methodology provides a comprehensive evaluation of the natural gas resource and key E\&P issues by making major analytical advances in scope of analysis units, full volumetric accounting for gas resources, and efficient preprocessing that allows for more extensive analysis than is now possible. However, these assessments will not be complete without further analysis and integration to determine how the market for natural gas impacts technology commercialization and reservoir profitability. The following sections describe how GSAM analyses can be integrated into the full-system gas market.

\section{Demand and Integrating Module Methodology}

Traditional technology appraisal methods which estimate the impact of new technology on selected resources are inadequate to derive the full benefits of R\&D. The GSAM methodology developed to date goes beyond evaluating gas supplies to explicitly modeling the full impact of technology and policy changes on the timing and magnitude of technology commercialization. Natural gas cost reductions due to improved technology may have limited value if they fail to stimulate production to meet market demand. Despite lower costs of producing specific segments of the resource, these supplies may ultimately be higher in cost to the end-user. To correctly and completely evaluate the market impact of various competing technologies and policies, GSAM includes a comprehensive model of the downstream 


\section{Table III-1. GSAM Supply Model Components}

1. Natural Gas Resource Data - Contains raw data on reservoir location rock and fluid properties, production, reserves, and development history.

2. Resource Module - Generates explicit and complete reservoir descriptions for known and undiscovered/undeveloped resources. Estimates characteristics and numbers of undiscovered reservoirs and the characteristics of known reservoirs (including, as appropriate, those reservoirs of record that are not explicitly identified in the database). Assigns individual reservoirs to fields and plays based on available information. Implements defaults as needed to pass complete reservoir descriptions to the Undiscovered Undeveloped and Developed Resource Databases.

3. Undiscovered/Undeveloped Resource Database Comprebensive database that characterizes the numbers and properties of typical reservoirs of each field size class for each identified natural gas play. This database describes about 1,000 typical undiscovered reservoirs (100 significant gas plays with 10 size classes per play).

4. Developed Resource Database - Same format as the Undiscovered/Undeveloped Resource Database, but includes data on current development/production status to define alternative future development options. This database includes an additional, composite reservoir for each play representing all known reservoirs that are not identified in the database, most likely to be the smallest discovered reservoirs. These "pseudoreservoirs" are needed to reconcile model results to booked reserve estimates and currenthistoric production data.

5. Undiscovered/Undeveloped Resource Evaluation Module - Estimates well recovery and economics for initial reservoir development (to "wide spacing") by size class and play under alternative technology and cost assumptions. Explicitly evaluates the effects of reservoir heterogeneity on production potential and economics. Estimates impact by evaluating three wells characterized by a distribution of those reservoir properties that affect storage and deliverability or other reservoir engineering components. The property distributions will be defined for each play type. Production profiles for initial development wells will be stored for use in the analysis modules. Minimum acceptable supply prices for exploration, development, continued development, and continued operation will be calculated and required elements stored for use.
6. Developed Resource Evaluation Module - Evaluates known reservoirs to determine current development status and estimates potential for additional drilling, reserve addition, and production options. All reservoirs evaluated are either already developed to wide spacing, partially infilled, or approaching abandonment. Reservoirs are characterized based on current development status and incremental economics to continue current production and evaluate all possible additional development options. Fully characterized reservoirs are passed to the Developed Reservoir Bank.

7. Undiscovered Reservoir Bank - Contains information on all reservoirs not yet discovered or delineated by a new field wildcat well. Economic evaluation results, including required gas price to initiate exploration and development, and data on cost to continue development and production (in the event of decreased gas price), are contained in the file.

8. New Reservoir Bank - Contains all reservoirs discovered by the Exploration Module, including reservoirs that will be discovered by infield wildcats (new reservoirs in old fields). The file also contains economic analysis results including capital, drilling, sunk cost-basis required wellhead gas prices, indices to typical reservoir production profiles, and other data used to select newly discovered reservoirs for initial development. Reservoirs discovered by new field wildcats are aggregated in the bank by size class and play (roughly a 10 size class by 100 play matrix). In each model time period, successful new field wildcats "deposit" reservoirs to the bank and some portion of recently discovered reservoirs are "withdrawn" (i.e., developed).

9. Developed Reservoir Bank - Identical in structure to the Undiscovered and New Reservoir Banks. Provides development status of all known reservoirs and indicates the potential production and economics for alternative additional development options. Unlike the New Reservoir Bank that has "deposits" from the exploration module, Developed Reservoirs are only "deposited" once, at the beginning of the GSAM run. However, they are "withdrawn" rather rapidly since this bank feeds the Developed Reservoir Production Module, which implements ongoing development plans, and are then passed to the Additional Development Module. 


\section{Table III-1. GSAM Supply Model Overview (Continued)}

10. Technology/Cost/Geology Assumptions - Represents userspecified or default technology performance assumptions, regional/resource-specific cost data, and geological assumptions on intrareservoir property distributions. Intrareservoir property distributions will be based on geological appraisals of typical reservoirs in several generic play "types" (to be defined, but broadly based on lithology, depositional environment, or other gross factors that would significantly influence well-to-well distribution of reservoir properties). The technology assumptions used will impact both the preprocessing modules, as well as the Exploration, Initial Development, Known Production, and Additional Development Modules. Technology advances can be modeled as either improved performance, reflected in higher volumes of gas production as predicted from typecurve analysis, improved economics, lower costs or accelerated production, or some combination.

11. Exploration Module - Estimates the distribution of reservoir size classes discovered by successful new field wildcats (NFW). The efficiency of exploration adopts traditional exploration modeling concepts as well as new, technology-dependent ones. Success is modeled as the relative proportions of reservoirs discovered in various size classes for each successful NFW. The distribution actoss size classes is based on remaining reserves in each class, aggregate volume/area as a proportion of each size class in a drilling area (prospects in several plays are usually tested in the same drilling program), and the ability of exploration technology to characterize those parameters that are size- or volume-related. The outputs of the modules are the composite (expected value) finding rate for the next successful NFW, the minimum welthead gas price required to initiate exploration (including lease costs and dry holes), and the proportion of fields discovered in each size class. The Exploration Module "drills" NFW's in response to price signals and capital and drilling constraints issued by the Integrating Model. Exploration Module data outputs are passed to the New Reservoir Bank.

12. Initial Reservoir Development Module - "Develops" reservoirs in the New Reservoir Bank in response to price, demand, and constraint signals from the Integrating Model. Includes "suboptimization" algorithms to reflect imperfect demand and price signals as well as investment evaluation criteria other than minimum required price (e.g., reserve replacement, production maximization, differing utility functions, corporate distribution of investment opportunities). This module also handles major GSAM bookkeeping functions of vintaging production, capital expenses, and drilling.
13. Additional Development Module - Estimates the capital, drilling, reserve addition, production, and required price for two development options in all known and newly discovered fields that have already been drilled to wide spacing: (1) infill (one drill-down only) and (2) recompletion of existing wells. Development options are based on data supplied by the Developed and Undiscovered/Undeveloped Resource Evaluation Modules. Since the combination of changing wellhead gas prices, technology availability, and reservoir depletion continuously alter development option economics, options are evaluated and characterized so that results of these evaluations can be adjusted without rerunning the reservoir and cost modules. This module implicitly contains an "additional reservoir development bank" that is similar in format and operation to the New and Undeveloped Reservoir Banks, but indicates as available only those development options that are technically feasible and economic at the appropriate time. Finally, as for other development modules in GSAM, no optimization of infill options is anticipated for a given reservoir. A reservoir is infilled if it is preferred relative to other currently available options for that reservoir, eliminating the consideration of a currently economic reservoir "waiting" for advanced technology or higher prices.

14. Developed Reservoir Production Module - "Completes" the current development phase of reservoirs in the Developed Reservoir Bank in response to price, demand, and constraint signals from the Integrating Model. Determines appropriate levels of production from existing wells, and the future production profile to the point where additional development can take place. Provides for curtailment of current production in producing reservoirs if wellhead gas prices decrease.

15. Other Gas Sources Module - Contains data and analytical modules on LNG, synthetics, associated gas and other potentially important or emerging sources of gas.

16. Remaining Resource Database - Repository for unproduced gas resource. Data on resource and marginal costs of next producible increment of gas for each identified reservoir are stored for future analysis. Provides full accounting of remaining gas resource by type (undiscovered, discovered/undeveloped, developed/uncontacted, contacted/uneconomic). Can be assessed during model run for quality control reasons or for further analysis (e.g., abandonments, evolving research targets, etc.). 


\section{Figure III-4. Major Components of GSAM}

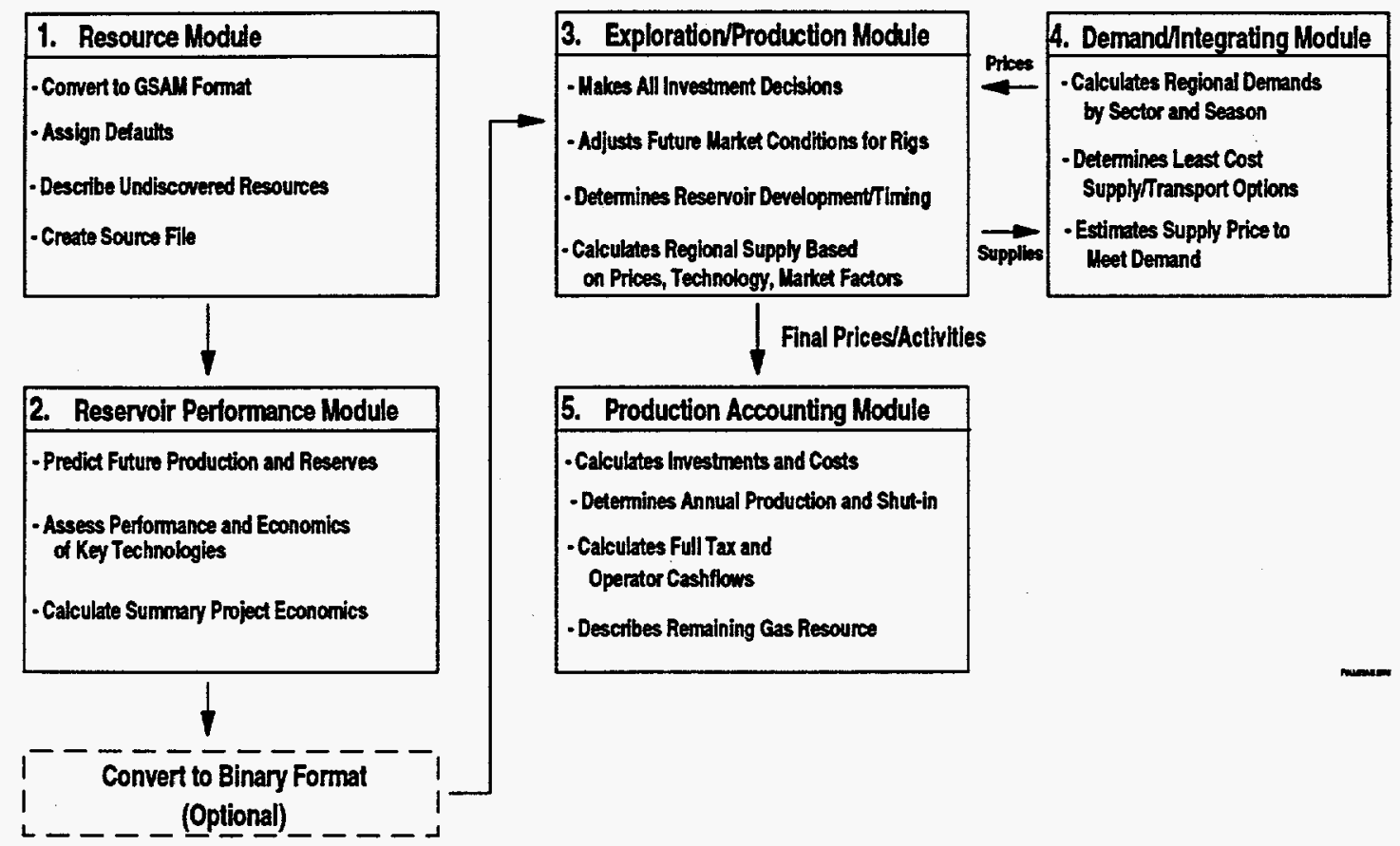

(gas demand) segment. Figure III-6 displays the logic and data flow of GSAM's current end use demand model.

Analysis of demand for natural gas includes regional assessment of consumption by sector. The proposed GSAM methodology uses existing models of residential, commercial, industrial, and electric utility requirements for gas to determine demand within 14 regions. The end-use projections rely on userspecified macroeconomic parameters (e.g., population, economic growth, and other factors) that directly influence the overall demand for natural gas. Inter-fuel competition is also explicitly analyzed within GSAM. End-users in the industrial and utility sectors have substantial fuel switching capacity, capable of using natural gas, oil, or coal as needed. GSAM explicitly analyzes the future impact of inter-fuel competition on regional and sectoral demand.

The Demand and Integrating functions provide the breadth and depth of evaluation consistent with the role of GSAM in E\&P policy and R\&D planning and evaluation. The regional equilibration of supply and demand is accomplished to provide realistic estimates of North American gas market performance. 
Figure III-5. Analysis of Natural Gas Resources by

GSAM Analytical Modules and Databases

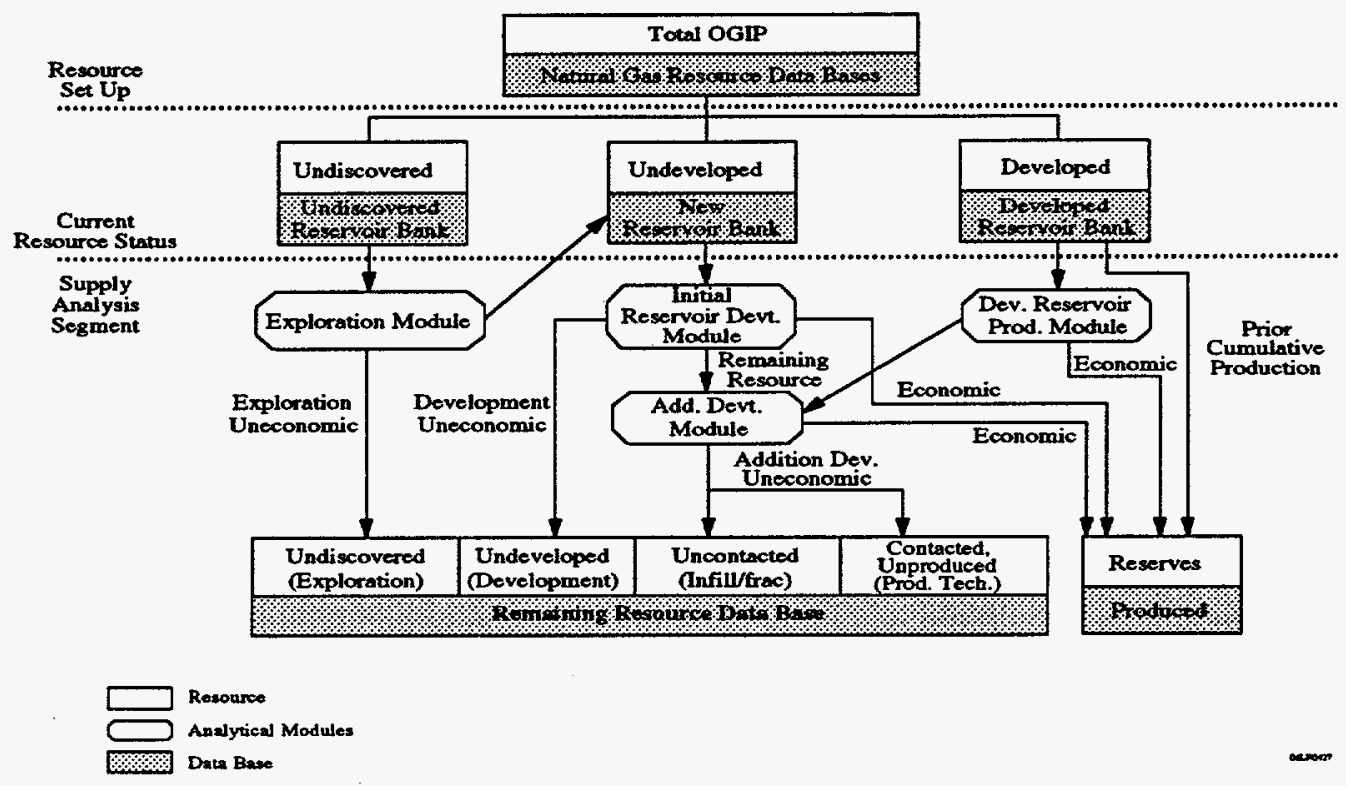

GSAM explicitly evaluates gas transportation and storage which are among the most important issues targeted by DOE's DNGOI. The ability of existing infrastructure to cost-effectively move gas to market is modeled by GSAM as 71 transport links between supply and demand regions. In addition, the integrated approach provides for the evaluation of adding capacity or new service pipelines when market limitations and economics dictate, accounting for seasonal demand fluctuations and storage and other peaking options. The explicit evaluation of seasonality provides METC a unique opportunity to evaluate storage reservoir performance, the need for additional capacity, and alternative strategies to merely developing more storage reservoirs.

The Integrating Model equilibrates annual gas prices and sales volumes over a 40 year period. The regional assessments of supply and demand must be reconciled to determine inter-regional gas flows and resulting regional gas prices. GSAM uses a linear programming technique to equilibrate gas price and volumes against physical capacity and economic constraints among and within 26 supply regions, 14 demand regions, and over 71 transport links (Figure III-7). 
Figure III-6. GSAM Demand Model Flowchart

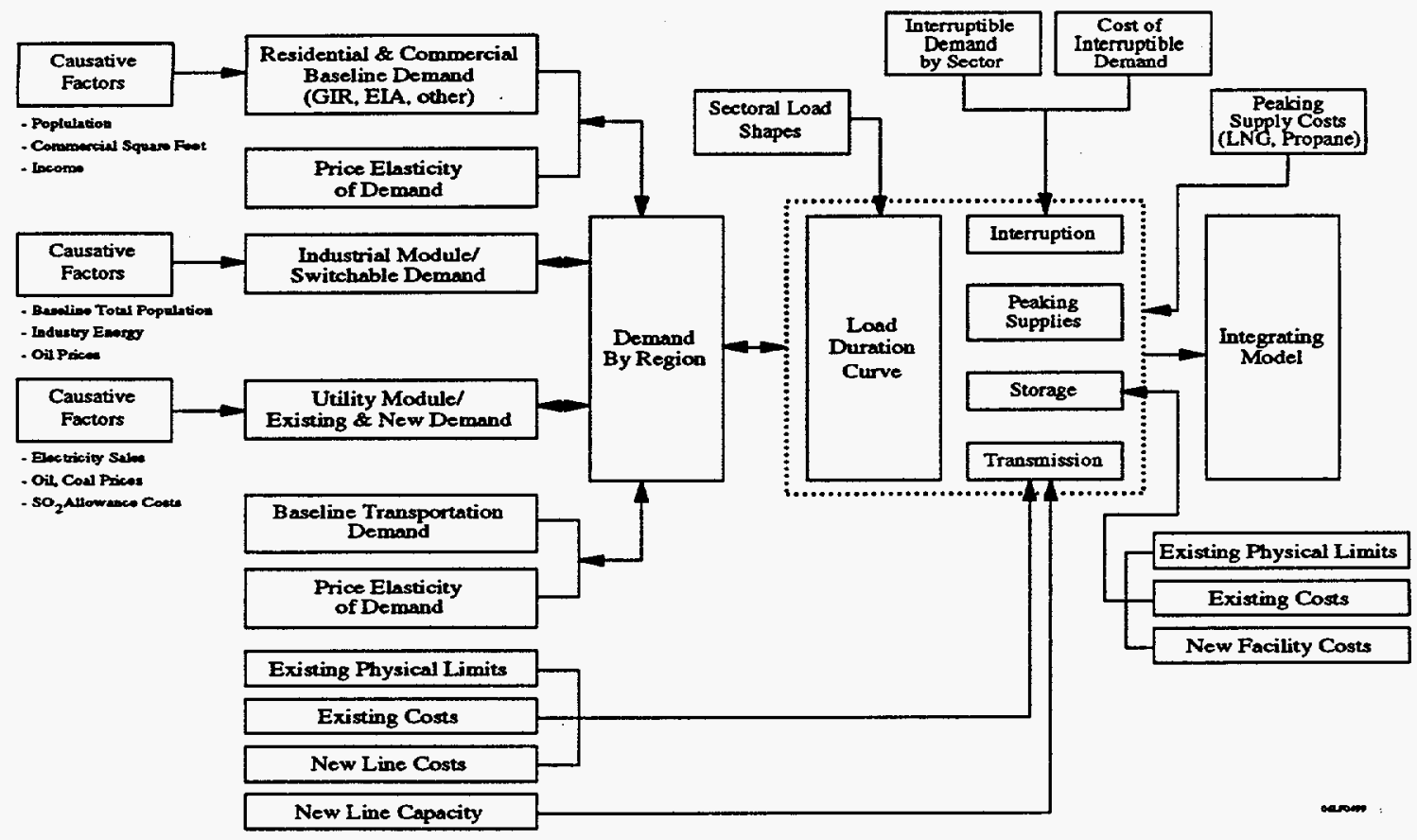

The Demand and Integrating Model also performs important accounting and equilibration of investments and available infrastructure, observing existing and probable future constraints. Similar to the Upstream and Downstream Models that provide input to it, the Integrating Model approaches decisions from an investor's viewpoint. It attempts to balance supply and demand in each region by the least-cost strategy that balances (fully risked) producer or consumer surplus, as appropriate. Figure III-7 shows the transportation infrastructure currently used in GSAM to estimate supply and demand balance.

\section{GSAM Outputs}

The results from the Integrating Model provide a verifiable and credible basis to forecast future gas supplies and prices, based on user-specified E\&P technology and policy assumptions. However, it also captures the resulting market events that are likely to impact demand for gas. The reports generated from this integrated market evaluation provides valuable insight into strategies for maximizing the current and future value of the domestic gas resource. 


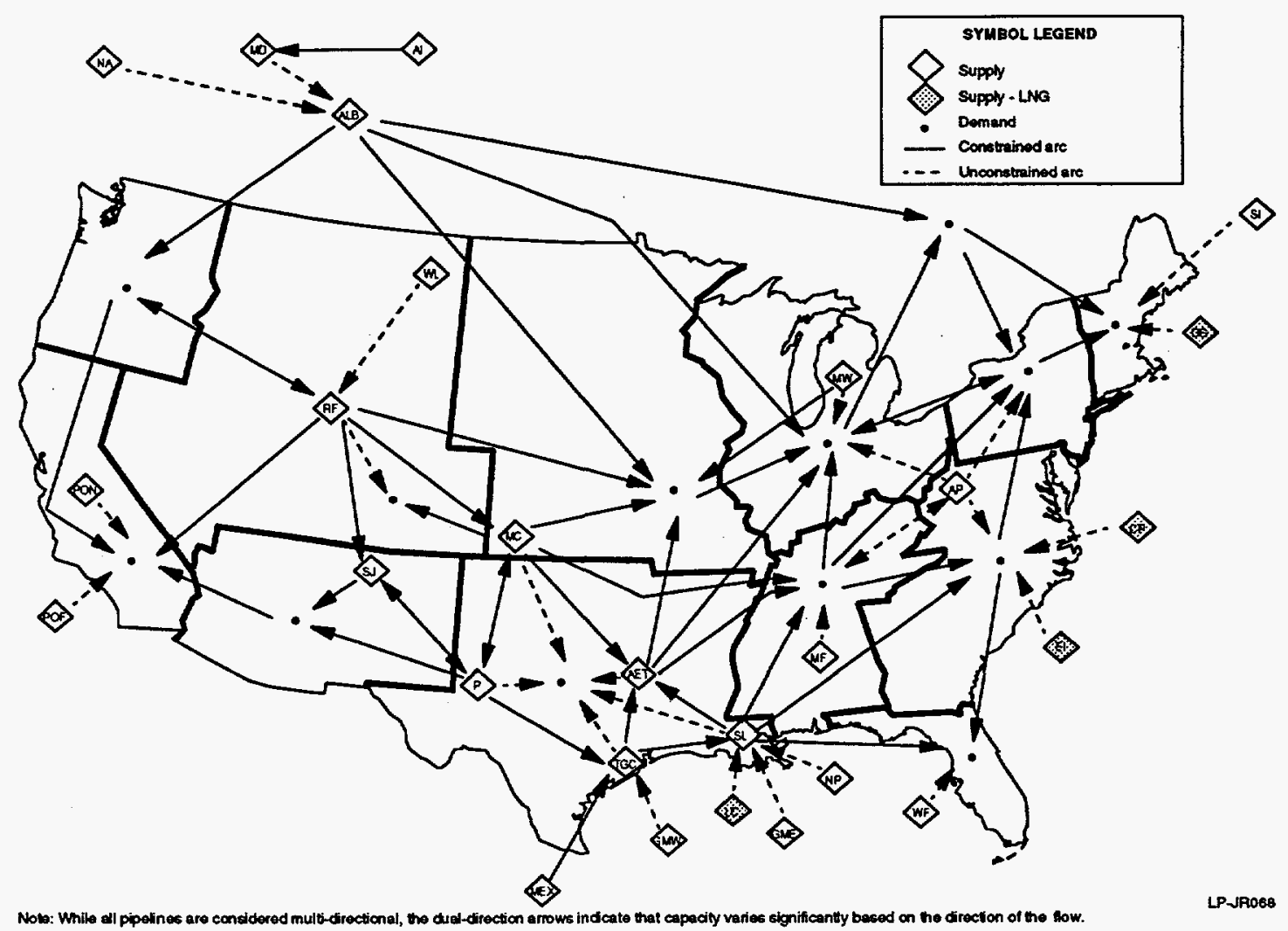

GSAM output is designed and formatted for flexible use in post-processing and extended analysis. Tabular reports are structured to allow direct export for use by spreadsheets, databases, and graphics software. Lotus 1-2-3 data file formats provide the basis for the design, which are generic enough to allow translation to other formats. The output formats for the various modules ensure easy compatibility with other systems models and databases.

GSAM output includes significant detail on production, consumption, technology use, resource status, and gas price by region over time. Additional economic variables detailing operator-view economic pro forma, as well as public sector benefit analysis, are also available from GSAM reports in the Production Accounting Module. The modular design provides the user with capabilities to focus analyses on items of interest and, by varying input or output options, create special application reports for use in further analysis. Additional information and flexible report formats are available to determine reservoirspecific production and economic summaries, regional, state or resource output, and national summaries. 
Potentially most important and relevant to DOE are the GSAM summary outputs of technologyrelated variables. Technology summaries, including the number, types, costs, and benefits of various applications, are provided in standard reports. Technology market penetration and applicability in various regions or specific reservoir settings can be derived from these standard reports.

Quality control indicators are also included in all GSAM output. Internal consistency and external congruity provide users with assurance of data and model validity and plausibility. The level of disaggregation in GSAM provides the potential to generate output in formats similar to other, more aggregate models for direct comparison.

\section{B. Database Development}

The domestic natural gas resource is diverse and $R \& D$ requirements depend on the unique physical, economic, and environmental settings of each reservoir. GSAM was developed to evaluate the unique characteristics of this resource and help managers determine the key research needs of various segments of the natural gas industry. For this reason, a comprehensive database was needed for GSAM.

During the past year, significant research was undertaken to develop resource descriptions for use in GSAM. This included the incorporation of information on known, producing reservoirs, description of the remaining undiscovered resource, and calibration with history and other estimates of natural gas potential. GSAM development was modified to provide research to construct the initial databases needed to test and use the model.

The data development phase of GSAM will be an ongoing effort. As new and updated information becomes available it will be incorporated into the database. The Peer Review committee made specific recommendations on the data structure and coverage that will be addressed. Recently, GSAM development was extended for a two year period, with significant effort devoted to data enhancement and validation. This effort will result in a complete, validated database for GSAM for use by METC and others in R\&D planning. 


\section{Requirements and Purpose}

The goal of initial data development was to create a set of databases to use in development and testing of the GSAM models and interfaces. To successfully complete this task, a database of known reservoirs containing information on key reservoir properties and production histories was required. NRG Associates database was selected for this based on a review of available sources. The detailed information contained in the NRG files provided all the required information for final GSAM development and was purchased by DOE and provided for use in GSAM.

Additional development of data for model testing involved accounted for resources not described in the known reservoir file. Reservoirs in Appalachia and Canada, as well as the undiscovered and unconventional resources, needed to be analyzed in order to thoroughly test GSAM. Initial research was devised to create descriptions of these resources, calibrated to published estimates of their potential future production capacity. This effort was completed during the past year and a complete GSAM database delivered with the GSAM models.

\section{Data Development Approach}

GSAM data development consisted of a three step approach. First known reservoirs were described based on available data from sources licensed by DOE. NRG Associates database of Significant Oil and Gas Fields of the United States served as the primary source of information on properties of these reservoirs. Additional data was added to GSAM by NRG, particularly for smaller gas reservoirs not included in the published database. This research provided a detailed description of over 8,000 known gas reservoirs nationwide.

The second step was to develop and implement a method to describe the undiscovered natural gas resource for modeling. For this, the U.S. Geologic Survey (USGS) estimates were used. The play level estimates of technically recoverable resources were cross-walked with NRG's cluster descriptions. This provided an estimate of the total resource contained in each play. Using resources assessment techniques that relate reservoir size distributions and finding rates, an initial undiscovered reservoir database was developed. This database was adjusted to more closely reflect the USGS assessed volumes. 
The third step was to account for missing reservoirs, including those in Appalachia and Canada. No data was found to be readily available to describe these reservoirs. However, regional production and reserves volumes are published. This information was used to create representative reservoirs to account for this resource. Initial descriptions were adjusted to reflect approximate production levels and reserve volumes in each region. Additional calibration is underway to more accurately depict the relative economics of development and production in these areas.

The databases selected and developed have been used to test and refine various segments of GSAM. Significant research was devoted to the modification of the Resource Module to allow additional analysis of the overall resource base. Work was also completed to develop default assumptions to account for missing data elements based on other elements in the file or based on average properties from other similar reservoirs.

\section{Additional Research Requirements}

Additional data development efforts have been proposed and approved for GSAM. These include updating existing data to reflect recent production (1993 and 1994), incorporation of new USGS estimates

that were recently released, better characterization of Appalachia and unconventional reservoirs, and development of the Canadian database based on newly available data. This effort was recently initiated and will substantially enhance GSAM.

The new work will result in a complete, documented set of databases for use in GSAM. The effort will provide additional analytical capabilities as recommended by the Peer Review Committee and compliment efforts associated with the Gas Atlas program and the Gas Information System (GASIS) development.

\section{Summary of Findings}

Based on research to date, data sources to account for all resource types have been identified, analyzed, and incorporated for use in GSAM. Methods have been developed to analyze, convert, and default key data elements for analysis in the typecurve and economics models of GSAM. 
Sources of updated data have been identified and are being collected for incorporation into GSAM. Estimates from the USGS of the onshore, undiscovered estimates are currently being converted for use in modeling consistent with developed methods for describing undiscovered reservoirs in diverse play settings. The Minerals Management Service (MMS) is scheduled to release similar estimates for federal offshore resources soon. These are also scheduled to be incorporated into the GSAM data system as well.

Canadian reservoirs are expected to contribute ten percent or more of the overall gas demand in the U.S. over the next several decades. Descriptions of this important resource are being enhanced in GSAM through data recently collected by NRG Associates. The full description and consistent analysis of Canadian gas reservoirs will substantially enhance GSAM's capability to assess R\&D impacts throughout the North American gas market.

Overall, the data development effort has been successful in utilizing diverse information sources to describe gas reservoirs nationwide. The expansion of data for Canada and offshore, as well as the updating of the undiscovered and known reservoirs throughout the country will substantially improve GSAM credibility.

\section{Peer Review Committee Meeting}

As planned, GSAM was reviewed by a panel of experts from the gas industry. The meeting of the committee was held in Pittsburgh on October 11 and 12, 1994. The two day meeting brought together over 30 participants invited by METC to observe and comment on GSAM development to date.

\section{Structure and Purpose}

The GSAM Peer Review process was designed to brief industry on the capabilities of GSAM while gaining important input on additional enhancement and required modifications to the approach and procedures in the models. The meeting was structured to make maximum use of the experts available to review various aspects of GSAM. METC wished to gain the maximum feedback possible on the current GSAM structure and possible approaches to make it more useful to DOE and possible future users. 
The overall purpose of the meeting was to identify and prioritize enhancement to the GSAM data and models. The input from these experts was deemed critical to final design and system development efforts. The recommendations of the committee as a whole and the various subgroups are briefly described below. A comprehensive report of the specific recommendations was developed and sent to committee members for review and to METC for final documentation of the meeting.

The committee consisted of 15 experts from various backgrounds. The overall committee was further split into three sub-groups to cover data development, upstream modeling, and downstream assessment methods. The full committee made final recommendations on the overall system based on findings of the sub-groups.

\section{Meeting Summary}

The Peer Review meeting was the culmination of several months of planning and research efforts to prepare and document key GSAM features. Prior to the meeting, committee members were called and briefed on the status of GSAM and the objectives of the review process. All members of the committee were provided with documentation of GSAM for review prior to the formal meeting.

In addition to the committee members, DOE invited a number of observers and guests. Attendance at the Peer Review meeting totaled over thirty experts from DOE Headquarters, the Bartlesville Project Office, Metarie Site Office, METC, and various contractors. Input was sought from all participants during the meeting.

At the meeting, the agenda included one-half day of overview of the entire GSAM system and key design aspects. This provided all members with a detailed background of the history and overall development efforts, as well as the goals of the final GSAM modeling system. To gain maximum value from the meeting, the committee then split into its three sub-groups to intensively review details of key GSAM components. The committee reconvened the second day to provide overall recommendations and priorities for future work. 


\section{Results and Recommendations}

The committee provided important technical input for the further development and expansion of GSAM. They specifically recommended the completion of a comprehensive GSAM database to include Canadian reservoirs, as discussed above. The sub-group reviewing the data also recognized the difficulty in describing individual reservoirs nationwide under diverse settings. They recommended additional nonGSAM evaluation of data reliability to ensure consistency and conformance of the data to METC requirements. Overall, the committee approved of the resource description approach and data structure developed for GSAM.

In addition, the committee recommended that the unconventional and water-drive typecurve modules be further assessed and possibly enhanced. Also, potential enhancement and testing of the exploration model and methodology was identified as a priority activity. The expansion of modeling capabilities related to gas processing was also recommended. They also recommended that an exploration expert review the approach. The committee will be provided with all documentation on GSAM development and future testing.

Several enhancements were also recommended in the Demand and Integrating Module. These included improvements in the pipeline characterization to better reflect future expansion capability and market risk, better characterization of energy competition, including the potential for transporting electricity between regions to meet peak demands, and some additional work on characterizing future industrial demand for gas. These recommendations have been incorporated into future GSAM plans.

\section{Model Development}

\section{Task Objective}

This task is the culmination of all GSAM work to date and the dominant activity during this period of performance. Its objective is the development and testing of the individual modules that constitute GSAM. The importance of this task is reflected in the detailed documentation requirements as described in the contract. Work on this task began with the development and full validation of all individual modules. Much of the essential testing of the modules has been awaiting the availability of 
resource data and is now in full operation. Full integration of the entire system was completed during the past year and testing and validation is underway.

\section{Development Approach}

As the GSAM methodology was finalized for each segment, a prototype module was developed. The entire GSAM model is coded in FORTRAN. This provides for the quick development of prototypes that can be easily expanded or replaced completely. These various prototypes were linked to provide an overall GSAM structure. As new information was obtained and new approaches to analysis developed, modules were replaced in enhanced updates. This modular approach has paid dividends in terms of time savings in design modification, testing, and overall model development.

The type curve modules that are the heart of GSAM's reservoir performance evaluation system, have been developed sequentially. The simpler pressure depletion, radial flow module was developed first to provide a working framework and starting point for other more complex settings. Six individual but consistent type curve modules were delivered and individually tested and integrated. The type curves have been fully integrated with detailed engineering and costing routines to complete project economic evaluations required in the Reservoir Performance Module.

The exploration module has also been fully developed and continues to be thoroughly tested. The final development of this segment of GSAM depended on availability of resource descriptive data. With the availability of NRG data, a comprehensive test database was developed. The contract modification will allow full integration and calibration of the exploration process model consistent with recommendations of the Peer Review committee.

The full upstream model has been integrated and data links checked, modified as required, and confirmed. Most of the work remaining in this segment is in validating results, calibrating input assumptions, and documenting procedures. This will be completed in accordance with the contract requirements for model documentation.

Work is underway to complete a comprehensive testing and validation of all components of GSAM. This will be completed under Task 5 of the contract and reported in a separate topical report. 
This step is also critical to the successful completion of the Peer Review meeting. The full plan for testing and validation will be provided along with the topical report on model development in July.

\section{Status}

Model development is complete and testing and validation is continuing. Full integration of all modules has been completed and all interfaces, inputs, and outputs continue to be tested. Validation and final calibration of the model is planned for next month. As new data is collected and added, model modifications will be implemented as required.

The full GSAM system has been installed at METC. As the system is updated, new versions of the data and models will be added on a continuing basis. METC users and key contractors have begun to review and test key GSAM components. Recommendations from users are incorporated into ongoing work, if possible.

Documentation on model development and the users' guide are in draft and being reviewed. The topical reports associated with contract Tasks 4 and 5 will be considered working documents, updated routinely to reflect new capabilities added during the contract period. Final documentation will be provided at key milestones for formal METC review and critique.

\section{E. Environmental Module Design and Development}

\section{Task Objective}

The development of the Environmental Module is designed to provide a useful analytic tool for examining the impacts of incremental compliance costs on future gas exploration, development, and production operations. Its purpose is to address most types of analytical requests that require the estimation of incremental compliance costs. This capability will assist DOE in many upcoming analyses. The Module will ultimately provide technology evaluation and benefits assessments as well. The task was also recently expanded to provide additional analytical capability related to selected regulatory compliance strategies. 


\section{Development Approach}

The Environmental Module has been designed and developed in stages. Initial data structure and compliance cost estimates are complete and can be used to conduct various policy and planning analyses now. Work is underway to develop a detailed descriptive module to outline regulatory specifications under various regimes. This will be integrated with benefits assessment work which is planned for next year.

Data development and prioritization is an on-going activity and will continue through the contract extension period. The development of benefits assessment to reflect the impact of various compliance efforts are also planned for GSAM. These features of the Environmental Module are more complex and will be developed following the initial tests of the compliance cost calculations.

\section{Research Completed}

Initial modular design has focused on the development of cost relationships associated with various compliance requirements. This included the initial development of a site-specific database and crossreference file. Detailed cost algorithms were developed and tested to accurately reflect the direct cost impacts of various regulatory scenarios on investments and operations. Initial assumptions about future environmental compliance requirements were analyzed and summarized as well.

The initial design, implementation, and testing of the Environmental Module is complete. The data and costing algorithms have been linked to the Reservoir Performance Module, the Exploration and Production Module, and the Production Accounting Module. Additional modifications and enhancements have been approved and design of these are being completed now. An updated work plan is also being developed for submission to MSO and METC for approval. 


\section{Research Results}

\section{A. Results Achieved During Period of Performance}

GSAM's highly disaggregated resource and technology characterization allows it to assess alternative federal natural gas $R \& D$, tax, regulatory and environmental policy initiatives at a previously available level of detail. It will also be available to industry to support capacity planning and market analysis for various end-users and provide comprehensive gas industry environmental impact assessments.

GSAM models and databases are now fully developed and work is underway to calibrate the system. Relevant natural gas upstream, downstream, and market models were reviewed to identify appropriate analytic capabilities to incorporate into GSAM. We also reviewed commercial gas extraction technologies to better characterize performance and costs in terms of GSAM parameters. Models were also evaluated to determine appropriate methods and needs for linking to GSAM through modified input or output structure.

GSAM operates on a DOS platform and currently runs on a Pentium 90 machine with $16 \mathrm{MB}$ of RAM and 1GB of hard disk storage space. Consistent with contract requirements, it has been tested and can operate on a 486DX2/66 machine with $12 \mathrm{Mb}$ of RAM and $250 \mathrm{MB}$ of available hard disk. However, run times can be excessive if disk space is limited. The hardware requirements of GSAM will be reevaluated as part of the Peer Review to determine if any model changes are desirable. A user manual was developed and is under review by METC and initial users. A priority has been given to improving run time efficiency and minimizing data storage requirements.

Full GSAM model and data development was completed over the reporting period. The design of the databases, modules, and interfaces was finalized. Design specifications for the individual process and economics modules, quality control procedures, and databases were fully developed to provide a framework for final design and integration, which has proceeded rapidly and is nearing completion. Topical Report 4 summarizes the full research findings surrounding GSAM methodology development. 
GSAM design, model development, and database structuring was also largely completed during the period. All individual modules have been developed and tested through a series of calibration runs. Final modifications to the type curve reduced form model for unconventional resources (coal and shale) were implemented based on a new approach based on previous findings. Current activities are focused on improving the speed, accuracy, input and output specification, and storage requirements of the overall system. This is proceeding concurrent with testing and systems validation. This activity will culminate in the preparation of Topical Report 4, GSAM Model Development. This report will provide the framework for briefing the Review Committee.

\section{B. Research Difficulties and Methods Developed to Overcome Them}

All significant limitations to research and model development were addressed and overcome given the recent modification to the contract. Documentation is being completed which will complete initial GSAM development. No additional obstacles are currently anticipated in final GSAM development. 


\section{Planned Research Activities}

GSAM development is entering into a critical final year of testing and validation. Significant work remains to calibrate and fully document individual components and the Integrating Model. Additionally, recent modifications to the contract are being planned and scheduled for full implementation over the period from now until June 21,1996 . This section outlines the remaining work to complete GSAM: develop and integrate the environmental module, construct and test a comprehensive gas resource database, and complete a through technical review before a panel of industry and government experts.

\section{A. Final Model Integration and Testing}

As discussed above, work to fully integrate and test GSAM is currently ongoing and will be complete prior to a meeting of the Peer Review Panel. GSAM structure and design will be finalized with the completion of the individual upstream modules, the reservoir database developed using the NRG database, and the integration and interface with the downstream model complete. Testing and validation will involve a large number of sensitivity analyses over a broad range of market, technology, tax, and cost conditions. The goal is to ensure that the modules, each of which has been individually tested, are appropriately linked and calibrated.

This activity will be integrated with the resource data development discussed below and submitted to the Peer Review panel for comments. Based on recommendations of the panel and various subcommittees, the final GSAM design will be modified and models enhanced. This approach is designed to produce a highly relevant system with maximum value to METC for strategic R\&D planning, program evaluation, and policy evaluations.

\section{B. Environmental Module}

The basic structure of the Environmental Module is shown in Figure V-1. The locational crossreference file has been preliminarily developed and serves to translate data at various levels of aggregation to the reservoir level for use in GSAM analyses. The volume of environmental data that could potentially 
be included is large. ICF plans to work with DOE to establish priorities for data inclusion. The Environmental Module supplies data to the GSAM technology, cost, and economic routines, preprocessing the data for each reservoir and transferring information to GSAM in terms of dollars per well, dollars per foot, dollars per barrel of water produced, or dollars per thousand standard cubic feet (Mcf) of gas processed. Figure V-2 illustrates the data retrieval and processing procedure associated with the Environmental Module.

The 1992 study by the NPC of the Potential for Natural Gas in the United States included an evaluation of the potential impact of environmental regulations on gas supplies. ICF supported the NPC in this analysis, which relied primarily on regional variation in compliance costs. The NPC study provides an excellent basis for the initial testing and verification of the operations of the GSAM Environmental Module. With the initial design and development of the Environmental Module complete, the compliance cost data and assumptions used by the NPC can now be input to the Environmental Module databases. GSAM will then be run using the same incremental compliance costs as used in the NPC analysis. The results will then be compared with those from the NPC study. Since the NPC study used the Hydrocarbon

Figure V-1. Structure of GSAM Environmental Module

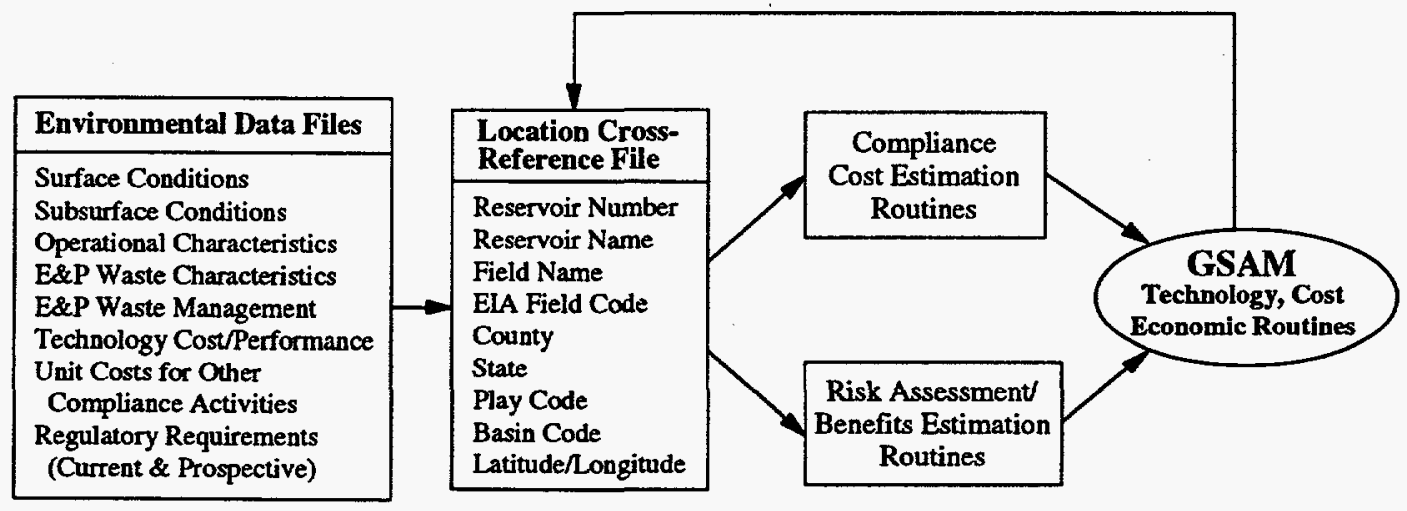




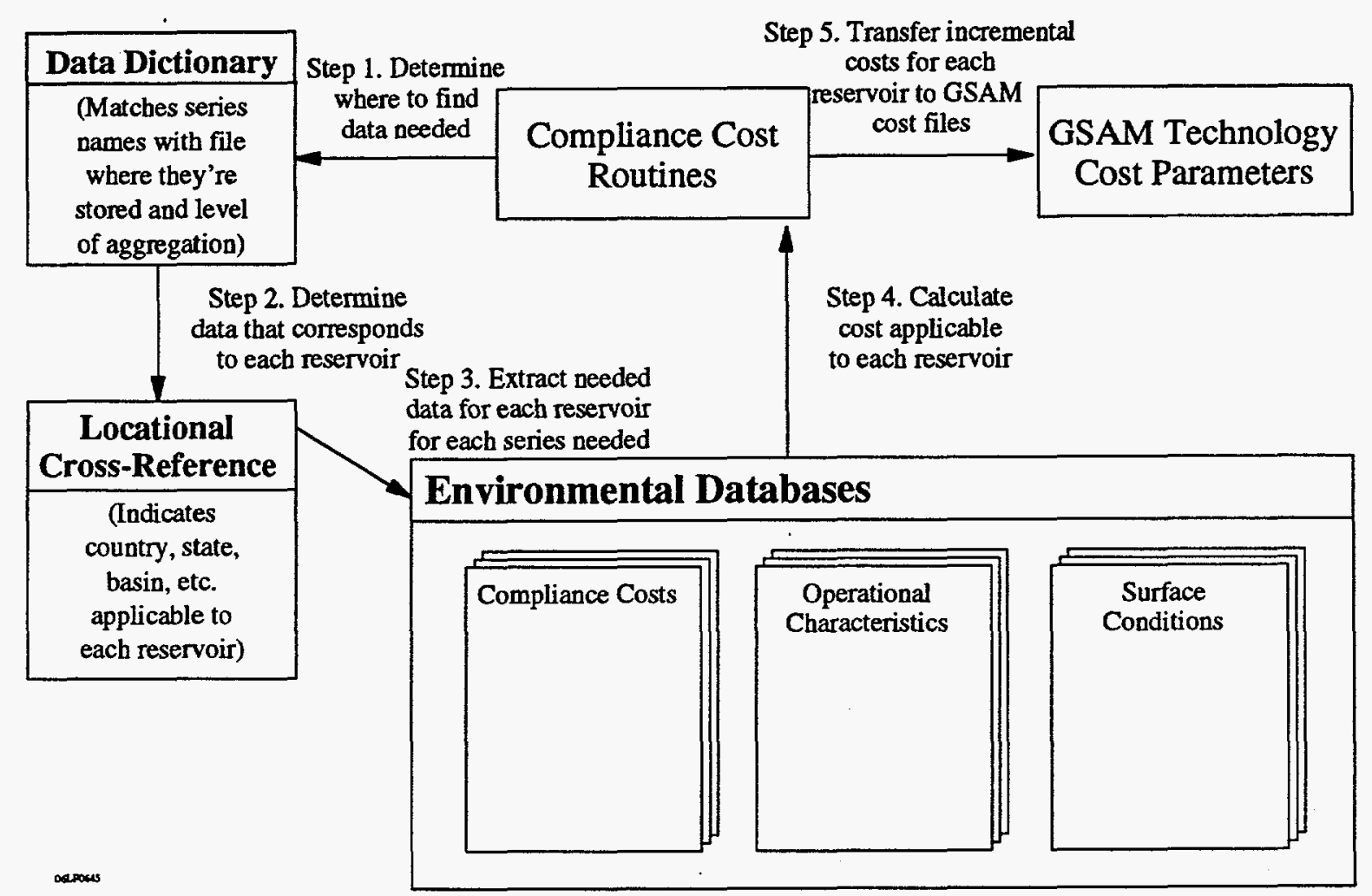

Model, which has some limitations that GSAM has been designed to overcome, the results from GSAM are unlikely to be identical, but they should be comparable. Subsequently, data at a more disaggregated level (e.g., state, county) that can be used to develop more specific costs based on the NPC scenarios will be input to the database. Another run of GSAM using the more disaggregate level data can be compared with the initial run using the NPC costs. This will provide a second test of the Environmental Module and begins to illustrate the benefit of using more disaggregate level data for analysis.

The development of the Environmental Module provides a useful analytic tool for examining the impacts of incremental compliance costs on future gas supply. It can currently address most types of requests that require the estimation of incremental compliance costs to assist DOE in any upcoming analyses. The technology evaluation and benefits assessment features of the Environmental Module are more complex and will be developed following the initial tests of the compliance cost calculations. Figure V-3 graphically displays the primary steps involved in the development of the Environmental Module. 
Figure V-3. Approach to Environmental Module Development

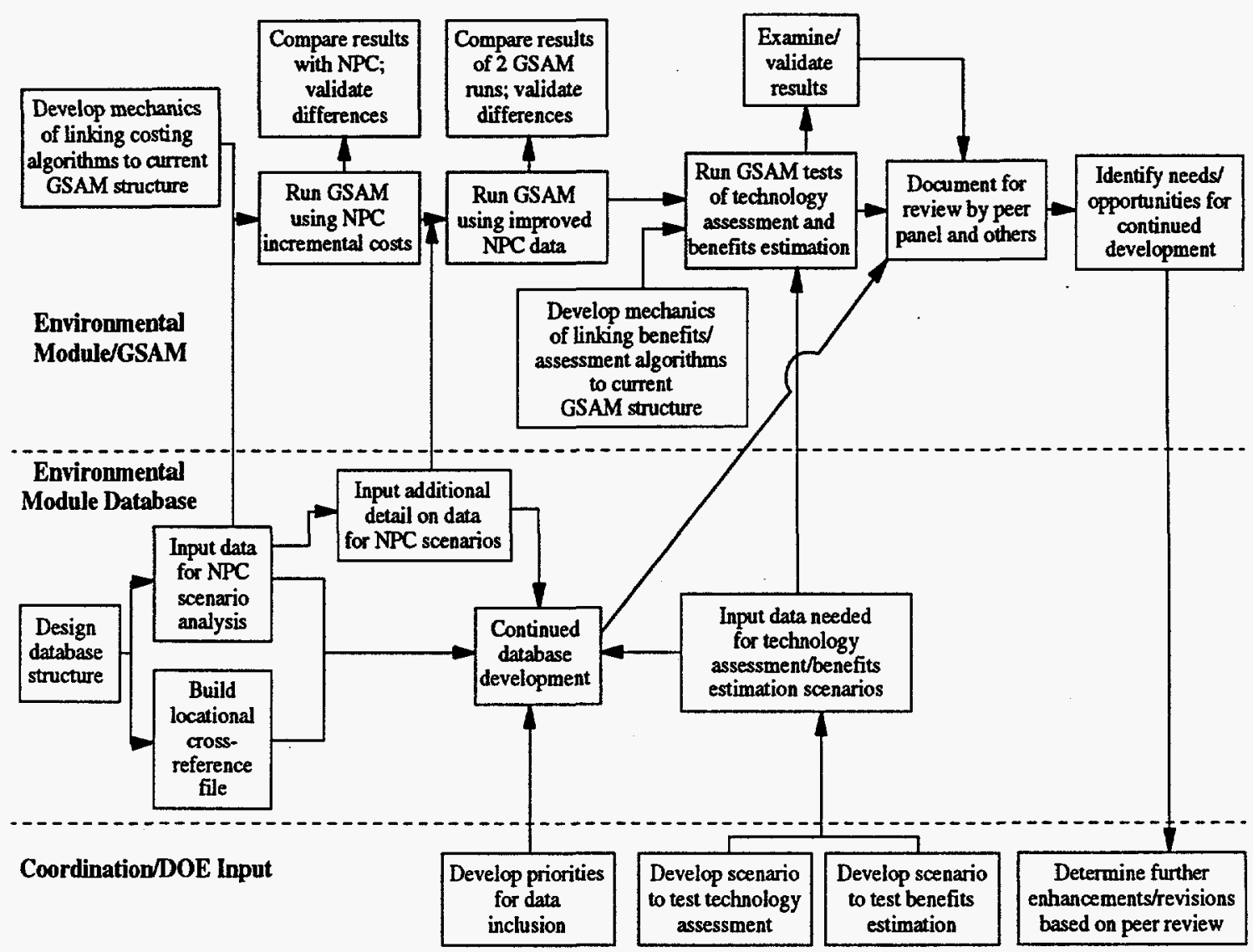

arrows

The planned deliverables for the Environmental Module include:

- $\quad$ Addendum to Task 3 methodology development report

- $\quad$ Addendum to Task 4 model development report

- $\quad$ Addendum to Task 5 testing and validation report.

These reports will be prepared as each aspect of the Environmental Module is completed.

When complete, the Environmental Module will have the following primary capabilities designed to assist DOE: 
- Incorporate site-specific incremental environmental costs and technology performance in a GSAM analysis to determine the impact of a regulatory or technology change on production, reserves, price, and costs.

- Estimate the benefits of a regulatory or technology change (in terms of wastes generated and potential risks posed) for comparison with costs of compliance and impacts found.

- Assess the benefits of various research projects in terms of achieving the same level of protection at a lower cost or achieving greater protection at the same cost.

The design of the Environmental Module is flexible enough that it can serve a range of other DOE analytical needs.

The expansion of GSAM to directly address environmental policy issues, consistent with the expansion of GSAM data to allow such detailed assessments, will substantially broaden system capabilities. This should enhance the future use and overall accuracy of GSAM in policy evaluations. Previous experience in analysis of domestic oil reservoirs has allowed this task to be quickly structured, planned, and will ultimately hasten and shorten data collection work.

\section{Resource Data Enhancement}

METC recently extended the contract for GSAM and added additional tasks designed to enhance the resource databases of GSAM. The current data has been used to test and validate the models and interfaces of GSAM. The initial testing and validation of the system has demonstrated the need for comprehensive data development in all segments of the natural gas resource.

As discussed above, during the next year, ICF Resources will expand and update the GSAM databases to reflect new information that becomes available. This will include a complete update of the undiscovered resource database, modification of the known database for Appalachia, Canada, and offshore regions, and refinement of the known reservoir datafile based on NRG data. Additionally, data on the unconventional resources, including tight sands, coalbed methane, and shales will be reviewed in the context of model development activities. Updates to the database will be provided to METC as work is completed and tested. 


\section{Model Enhancement and Validation}

During the upcoming year, model enhancements will be limited to those required to correct problems associated with new reservoir descriptions. Recent modifications to the contract to expand modeling capabilities, to evaluate gas processing techniques and to update reservoir modeling and exploration assessments will be completed after the data development is complete.

Topical Report 4 on model and data development is in draft and under review. Similarly, the Users' Guide has been submitted for initial review and critique. These documents provide significant detail on the current capabilities and operating procedures for GSAM. Each document will be continually updated as new data is added or models are modified. Currently, ICF Resources plans to submit several interim reports as new developments dictate. After review by experts, the process for exploration assessments will be modified based on recommendations approved by METC.

Validation and calibration of the models will be ongoing during the next period. Topical Report 5 will be submitted in draft in August based on findings and testing so far. This report will be updated as new data and modeling enhancements warrant.

\section{E. Review Committee Meeting and Follow-up}

The extension of the contract calls for the reconvening of the Peer Review Committee. The process of GSAM review by the committee will be expanded substantially in the next year. All members of the original committee, plus new members selected to review the Environmental Module and the exploration assessment methods, will be provided with all topical reports and summaries once they are reviewed and approved by METC. Also, as new findings require consultation, researchers will contact individual members of the committee to get input on options before significant work efforts are undertaken.

A formal meeting of the Peer Review Committee is anticipated during the next year. This meeting will build off the success of the first meeting and attempt to address all concerns and objections raised by the reviewers. In addition, a more formal follow-up procedure will be undertaken to keep committee members current on GSAM development after the formal meeting. 


\section{Conclusions}

Initial GSAM development is complete and documentation is being finalized. Initial testing and validation is complete for all modules, and system integration testing will be completed shortly.

GSAM is being expanded in the areas of environmental evaluation, the development of a comprehensive reservoir-level resource databases, and initial application of the system for program and policy planning. This will complement existing GSAM design and allow for more comprehensive evaluations of a range of $R \& D$ and policy alternatives. The initiation of these tasks will also now allow preliminary review of findings from the work by the GSAM Review committee.

Work planned for the next contract year will result in an enhancement of the system, thorough testing, validating, and calibrating. The revised model will be reviewed again by the Peer Review Committee. The next review will expand on the past meeting to include a more complete review of exploration evaluations and to include the environmental module.

Once revised, GSAM will be the R\&D planning tool needed by METC to comprehensively assess benefits of the gas program. The benefits of GSAM development will also accrue to both DOE and industry, as research is focused on the critical areas most affecting gas marketability. With this potential, the future of GSAM is an exciting and dynamic one. 


\section{Appendix A - GSAM Research Work Breakdown Structure}

Research activities are planned using this WBS:

2.0 Identify, Collect, and verify most recent data

2.1 Integrate additional/updated reservoir data

2.2 Collect and Integrate Industry Data

4.1 Update GSAM Model:

4.1.1 Finalize Reservoir Models

4.1.2 Enhance Exploration Model

4.1.3 Implement Gas Processing Model

4.1.4 Topical Report 4: Interim report model enhancements

4.1.5 Topical Report 4 draft final report

4.1.6 METC reviews report and comments

4.1.7 Topical Report 4 final report incorp METC comments

4.3 Implement System Integration/Enhancements
4.3.1 Canadian Resources
4.3.2 Unconventional Resources
4.3.3 Undiscovered Resources
4.3.4 Appalachia
4.3.5 Pipelines
4.3.6 Industrial Gas demand
4.3.7 Gas/Electricity
4.3.8 Topical Report 4 data enhancements/action plan
4.3.9 Topical Report 4 update undiscovered resource assessment
4.3.10 Topical Report 4 document all data enhancements
4.3.11 Validate Database for Appalachia, Canada, unconventional
4.3.12 Topical Report 5 system validation draft final
4.3.13 Topical Report 5 system final version with comments

4.4 Environmental Module

4.4.1 Update Database

4.4.2 Develop Windows Module

4.4.3 Downstream Methodology Development

4.4.4 Environmental Technologies Assessment

4.4.5 Environmental Benefits Assessment

4.4.6 Integration and Testing of System

4.4.7 Topical Report 4 Update Model Development Report 
4.4.8 Topical Report 5 Updated report with testing validation

4.4.9 Topical Report 4 Final Report

4.4.10 Topical Report 5 Final Report

5.0 Peer Review

5.1 Peer Group Meeting Preparation

5.2 Peer Group Meeting

5.3 Peer Group Meeting follow-up report

7.0 Policy Evaluation

7.1 Perform Evaluations

7.2 Support DOE

8.0 Final Research Report

8.1 Draft Final Research Report

8.2 METC Reviews Research Report

8.3 Final Research Report 